\title{
Article \\ The Effects of the Maternal Health Improvement Project in the Louga Region of Senegal
}

\author{
Babacar Ndiaye ${ }^{1}$, Louis Thiam ${ }^{1}$, Gahee Ham ${ }^{2}$, Yunsung Choi ${ }^{2}$, Eunmi Lee ${ }^{3}$, Kilho Kang ${ }^{4}$ and Youngran Yang ${ }^{5, *}$ \\ 1 Plan International Senegal, Louga 21121, Senegal; babacarndiaye47@yahoo.fr (B.N.); \\ Louis.THIAM@plan-international.org (L.T.) \\ 2 Plan International Korea, Seongnam 13494, Korea; hamgh@plankorea.or.kr (G.H.); \\ choiys@plankorea.or.kr (Y.C.) \\ 3 College of Nursing, Jeonbuk National University, Jeonju 54896, Korea; diazepam4@jbnu.ac.kr \\ $4 \quad$ VF Partners, Seoul 06732, Korea; khkang@vfp.co.kr \\ 5 College of Nursing, Research Institute of Nursing Science, The Center for Sustainable Development, \\ Jeonbuk National University, Jeonju 54896, Korea \\ * Correspondence: youngran13@jbnu.ac.kr; Tel.: +82-63-270-3116
}

check for updates

Citation: Ndiaye, B.; Thiam, L.; Ham, G.; Choi, Y.; Lee, E.; Kang, K.; Yang, Y. The Effects of the Maternal Health Improvement Project in the Louga Region of Senegal. Int. J. Environ. Res. Public Health 2022, 19, 396. https:// doi.org/10.3390/ijerph19010396

Academic Editor: Kuo-Hu Chen

Received: 3 November 2021

Accepted: 27 December 2021

Published: 30 December 2021

Publisher's Note: MDPI stays neutral with regard to jurisdictional claims in published maps and institutional affiliations.

Copyright: (C) 2021 by the authors. Licensee MDPI, Basel, Switzerland. This article is an open access article distributed under the terms and conditions of the Creative Commons Attribution (CC BY) license (https:// creativecommons.org/licenses/by/ $4.0 /)$.

\begin{abstract}
Maternal mortality remains a major global health challenge in sub-Saharan Africa. Senegal is one of the countries in the region that lagged behind in reaching the Millennium Development Goal 5, the deadline of which passed in 2015. The objective of this study was to assess the effects of information, education, and communication (IEC) activities conducted in Louga, Senegal. Community groups and facilitators conducted IEC campaigns, home visits, and various awareness-raising activities. This study used secondary data as part of the baseline and mid-term evaluations. Participants included women and men who had one or more children under five years of age. It was found that the level of awareness of at least three danger signs of pregnancy recognised by men significantly increased, and husbands/partners more frequently accompanied their wives during antenatal care in 2019 than in 2018. Women's empowerment improved significantly in terms of women making their own health decisions, joining community decision-making associations or groups, and using contraception. This project indicates that policies and programs are needed to increase men's involvement and empower women to further women's reproductive health to achieve the Sustainable Development Goal 3 and reduce maternal mortality in Senegal.
\end{abstract}

Keywords: antenatal care; contraception; danger signs of pregnancy; maternal health; maternal mortality; Senegal; IEC activities

\section{Introduction}

According to the latest World Health Organization figures, every day in 2017, approximately 810 women died from preventable causes during pregnancy or childbirth. Almost all of these deaths (94\%) occurred in low- and lower-middle-income countries. Sub-Saharan Africa is the continent most affected by such deaths. The high number of maternal deaths result from inequalities in opportunities to use quality health services and represents the gap between rich and poor countries. The maternal mortality rate (MMR) in low-income countries in 2017 was 462 per 100,000 live births versus 11 per 100,000 live births in high-income countries [1]. These overwhelming figures highlight maternal mortality as an urgent public health issue in developing countries. To fight this issue, one of the Millennium Development Goals (MDG5) was to reduce maternal mortality by three-fourths by 2015, making low-risk maternity a priority [2]. Taking fresh impetus from the MDGs, in 2015, the UN adopted a new sustainable development agenda, which focused on 17 sustainable development goals (SDGs) to substitute the MDGs. Under the SDG agenda, SDG3.1 has led to a new maternal health transformation initiative to end 
preventable maternal mortality so that the global maternal mortality rate can decrease to below 70 per 100,000 live births by 2030 [3].

Senegal lagged behind in reaching MDG5, a goal which had set 170 maternal deaths per 100,000 live births as its target. To achieve the SDGs and in line with Senegal's national policy based on the National Health Development Plan (PNDS), the country has made considerable efforts by launching several programs to reduce the burden of maternal, neonatal, and infant mortality. To meet these challenges, in addition to the PNDS, Senegal has defined a health policy that stresses on national strategic programs, including the National Family Planning Action Plan 2012-2015 [4] and the National Strategic Plan for Child Survival 2007-2015 [5].

According to a systematic review of nine low- and middle-income countries, programs engaging men during pregnancy, childbirth, and infancy resulted in improvement of antenatal care (ANC) attendance, facility birth, complications preparedness, and maternal nutrition, as well as male partner support for women and couple communication, and joint decision-making [6]. Many of these programs used the theory of change as a framework to coherently describe their project activity components, intended outcomes, and long-term goals. The Maternal and Child Health $(\mathrm{MCH})$ program implemented by the Ministry of Public Health of the Democratic Republic of Congo (DRC) improved the ANC utilisation by more than four times at the project site compared to the control area (odds ratio 2.280, 95\% CI: 1.133-3.902). The project included an educational program to increase the awareness of ANC through home visits, radio broadcasting, and signboards [7]. In a study of a community-based intervention program conducted in the Democratic Republic of Zambia, the provision of education on pregnancy and childbirth management increased the knowledge of women regarding 'pregnant women must receive ANC in early pregnancy' and 'three or more dangerous risk signs of pregnancy' by $24.7 \%$ and $7.1 \%$, respectively, compared to before the educational intervention. Furthermore, the intervention program reported that the delivery rate at medical facilities and the proportion of women who used contraception after childbirth increased by $25.7 \%$ and $10.6 \%$, respectively [8]. A study conducted in Ethiopia's Tigray region used small group education with the intervention group at the village level and educated them using bulletin boards to report higher increased rates of contraceptive use, prenatal management, facility delivery, and postpartum medical check-ups compared to the control group which was provided information using local radio [9].

Owing to effective interventions at both the clinical and community levels, Senegal has become one of the few countries where significant progress is being made in maternal and newborn health. The maternal mortality ratio decreased from 510 deaths per 100,000 live births in 1992 (District Health Information System DHS II) to 315 in 2015 (ANSD) [10]. However, the maternal mortality rate remains a concern, particularly in regions such as Louga (400 deaths per 100,000 live births in 2015), which are wide with remote and inaccessible health facilities. To overcome these challenges, Plan International Senegal, in partnership with Plan International Korea, launched a project to reduce maternal and child mortality in the health districts of Sakal, Keur Momar Sarr, and Coki in the Louga region. The goal of the three-year project 'Better Maternal Health' was to contribute to the reduction of maternal and child mortality in the region by improving the quality of health services, raising community awareness on reproductive health, and improving access to health services.

In the first year of the project, between July and September 2018, a baseline survey was conducted in the three target health districts. Subsequent to the baseline survey, after one year of implementation the mid-term evaluation of the performance measurement framework (PMF) occurred in June 2019 to collect relevant information that could help identify possible corrections applicable to the process, to optimise the implementation of activities, better meet the needs of the target populations, and identify relevant interventions for scaling up. This study used secondary data as a part of the baseline survey and mid-term evaluation to determine the effects of maternal health improvement by focusing 
on the changes in awareness of the danger signs of pregnancy, husbands accompanying their wives to ANC visits, women's acknowledgement of having received the support of the husband during pregnancy, delivery at appropriate health facilities, and women's decision-making about health, community activities, and contraception.

\section{Materials and Methods}

\subsection{Research Design}

This study used a one-group pretest-posttest design, to compare the before and after stages of the project implementation and determine the project's effect on maternal health in Louga.

\subsection{Study Area}

The data collection was carried out in the Louga region, particularly in the communes of the project's three target health districts, Coki, Keur Momar Sarr, and Sakal (Figure 1).

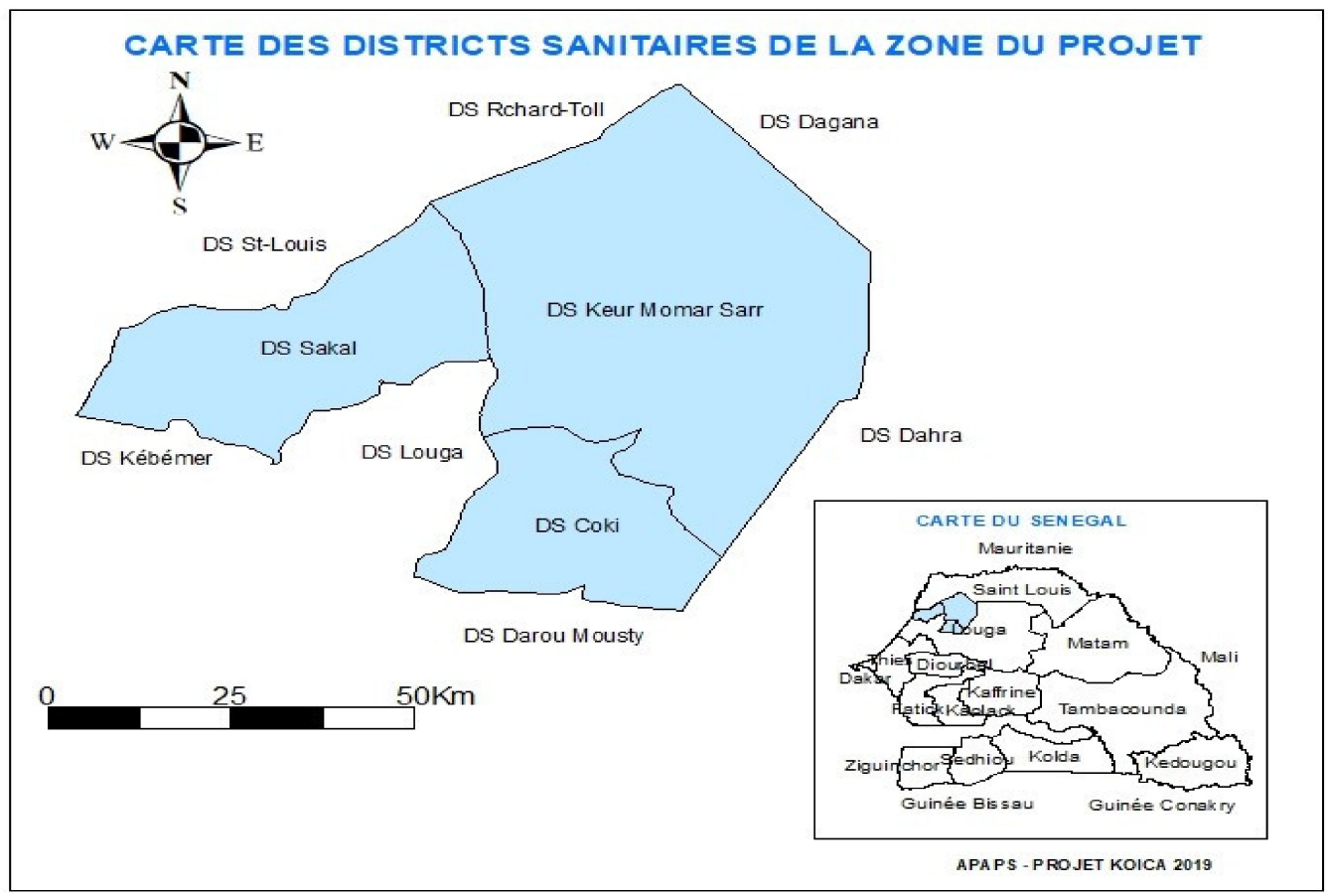

Figure 1. Area of the study.

\subsection{Study Participants}

The study participants were women of reproductive age (WRA) aged 15 to 49 years with at least one child aged under 5 years, and men aged 15 to 59 with a partner and with at least one child aged under 5 years. The participants were residents of the districts of Coki, Keur Momar Sarr, or Sakal. The WRA represented $24.2 \%$ of the total population in the study area. More than one third of the WRA (young people aged 15-19 years and adults aged 40-49 years) were at a high risk of maternal mortality.

\subsection{Sampling}

A random sample, representative of the health district, was drawn directly from the sampling frame using data from the 2013 General Census of Population, Habitat, Agriculture, and Livestock (RGPHAE 2013). First, each of the three health districts was subdivided into clusters [here, the RGPHAE Census Districts (RDs)] from which a random sample of census districts was drawn, followed by a subtracted draw within each census district sample. Finally, in each sample household, the WRA with at least one child aged under five years and the man of the household whose partner had a child under five years 
were interviewed. Thus, a 3-degree sampling method was used with the WRA and men as survey units. The optimal sample size for each stratum was determined using the Schwartz formula, with an accuracy of $5 \%$ and a confidence level of $95 \%$ based on the key indicator of the study, which represents the proportion of WRA who are users of modern contraception:

$$
n=\frac{t^{2} p(1-p)}{e^{2}}
$$

where

$n=$ optimal sample size to be sought;

$t=$ standard value (1.96) corresponding to the expected confidence level;

$p=$ estimated value of the selected indicator (proportion of WRA users of modern contraception; $e=$ degree of accuracy of margin of error at 5\% (typical value: 0.05 ).

According to the outcomes of the continuous Demographic and Health Survey (DHS) of 2016, the proportion of WRA using modern methods of contraception in rural areas was $17.2 \%$. Calculations using the Schwartz formula resulted in a survey size of 219 survey units as the optimal size of the WRA sample to be surveyed by stratum. This last figure, rounded to 220, was used as the size of the WRA subsamples to be surveyed by the health district. This resulted in a final size of 250 WRA samples per stratum, that is, 500 WRA for the two strata. No adjustment was made to consider the cluster effect and losses due to the small proportion of households that would be selected per cluster (or DR) and the high potential for replacements. This resulted in an optimal size of 220 WRA samples per health district, adding up to 660 WRA for all three districts. The same applied to the men who were surveyed in the same household as the WRA.

\subsection{Project Intervention}

Thirty-seven facilitators in the community groups (community-based organisations (CBOs)) and 22 project assistants were a part of the study. The facilitators conducted information, education, and communication (IEC) campaigns, home visits, and talks with the villagers. The project assistants supported the monitoring and supervision of these activities. Service quality management, which included sharing suggestions of the facilitator and project assistant evaluations conducted in the first quarter, was carried out.

A total of 1520 IEC campaigns, 9198 village-based informal talks, and 10,016 home visits were conducted, and a total of 292,461 (male 71,308/female 221,153) participated in these programs. The IEC campaigns were conducted with 30 or more people as a large group, and the facilitators used IEC materials for education. Village-based informal talks were carried out with a limited group of 15 to 25 people, in which facilitators interacted with participants during sessions, enabling participants to ask clarifying questions. Home visits were conducted for interpersonal awareness-raising activities in which the facilitators visited the targeted persons. During home visits, all health issues, including taboo topics, could be discussed with the facilitator and the facilitator also referred the pregnant women to the health facility. Through these three measures, various awareness-raising activities were carried out for residents, such as the importance of prenatal management, postpartum management, and male childbirth support. Details of the programs' contents included the following: maternal and child health knowledge and awareness of beneficiary populations regarding pregnancy-related risks, the number of ANC visits required during pregnancy, and the benefits of skilled delivery. The IEC activities addressed the attitudes and behaviours of the beneficiary populations regarding maternal health and gender equity issues, such as male partners' assistance to WRA before, during, and after delivery, and the level of support provided by the male partner in the female partner's decision-making processes.

A radio program on reproductive health and the benefits of getting medical insurance was conducted by a midwife on three radio rations. The program was intended to improve the awareness of those who have the right to make decisions at home, such as the elderly, 
but who have difficulty participating in awareness-raising activities through CBOs. During the project year, 251 radio shows were carried out. The facilitators conducted five meetings with the coordinators of the CBOs to coordinate and discuss activity progress, review evidence, follow regulations, activity priority, and activity plan.

\subsection{Data Collection}

Data collection was carried out simultaneously in the three health districts by 15 field staff. The staff members were split into three teams of four enumerators with a supervisor. For comparability of data, the data collection of the second-year study adopted the same techniques and tools as the baseline study. The survey data were collected from 7 August to 20 August 2018, for baseline and from 29 September to 10 October 2019 for the second year. The survey of socio-economic, demographic, and health data was carried out in the three health districts. In each sample census district of the household survey, the team supervisor contacted the local authorities to inform them about the purpose of the survey, the targets to be interviewed, and the expected practical arrangements. Once in a selected household, one of the enumerators proceeded to first inventory the household members to determine eligible participants (men and women). The enumerator then administered the questionnaire to eligible men and women after obtaining informed consent. The household survey was conducted in an electronic format (tablets). Once the questionnaires were completed, and checked by the supervisor, they were transferred daily to a server set up by the study agency. To ensure quality of the data, a second check for completeness and consistency was carried out by the management team.

\subsection{Measures}

'Awareness of the danger signs of pregnancy' was measured as being aware of at least three pregnancy danger signs. The participants were asked two questions, 'Do you know any danger signs related to pregnancy?' 'If yes, what are the danger signs related to pregnancy that you can quote?' (open questions). If the participants quoted more than three out of the nine signs (lack of foetal activity; convulsion; intense fever; severe, permanent headache/blurred vision; oedema of the face, hands, and legs; paleness; water loss; vaginal bleeding; and intense stomach pain), it was coded as having awareness of the danger signs of pregnancy.

'Husbands accompanying their wives during ANC visits' was measured by the question, 'Who accompanies you during ANC visits?' and among the options were husband/partner, mother, brother/sister, aunt, mother-in-law, sister-in-law, co-wife, friend, relay/matron, or nobody. 'Did your husband/partner support you during your last pregnancy?' Yes/No), was asked to assess the women's acknowledgement of having received support from their husband/partner during pregnancy. Delivery at appropriate health facilities included the options: clinic, health centre, health hut, health post, and hospital to the question 'Where did you give birth to your last child?'. Women's empowerment was measured by three aspects: making one's own health decisions ('Who generally makes decisions about your health care?' with the options only by wife, both husband and wife, husband/partner, or mother-in-law), joining a community decision-making association or group ('Have you joined a community decision-making association or group?' Yes/No), and disagreement with husband about the use of contraception ('Does your husband/partner forbid you to use a method of contraception?' Yes/No).

General characteristics were also obtained, including age, education level, marital status, ethnic group, and religion.

\subsection{Ethical Considerations}

Before data collection, the study was approved by the National Health Research Ethics Committee (CNERS) (approval number for the baseline survey: Ethical and scientific notice $\mathrm{N}^{\circ}$ 000084/MSAS/DPRS/CNERS dated 31 August 2018; for the midterm survey: $\mathrm{N}^{\circ}$ 000165/MSAS/DPRS/CNERS dated 6 September 2019). In compliance with the agreement, 
participation in the survey was anonymous and voluntary. Informed consent was obtained from all participants. In advance, they were informed of their right to refrain from participating or to withdraw from the survey whenever they wished without fear of reprisal. In the event of an agreement to participate in the study, the enumerator signed a consent form and gave a copy to the respondent.

\subsection{Statistical Analysis}

Collected data were analysed using descriptive statistics, including frequency and percentage, and a chi-square test or ANOVA was used to assess the effectiveness of the IEC activities before and after the intervention in the study areas. IBM SPSS Statistics for Windows, Version 21.0; IBM Corp., Armonk, NY, USA was used for data analysis.

\section{Results}

\subsection{Characteristics of the Participants}

The age structure of the women remained relatively stable and was marked by youth. More than a third of the women surveyed (39.0\%) in 2019 were under 25 years of age (compared to $34.8 \%$ in 2018). The percentage of 40-year-olds and above was still very low (6.7\% in 2018 versus $6.7 \%$ in 2019). The average age was 26 years in 2019 compared to 28 years in 2018. The percentage of out-of-school women was 53.3\% in 2019 and $65.2 \%$ in 2018. The percentage of respondents who had reached secondary school or higher slightly increased, from $2.0 \%$ in 2018 to $7.1 \%$ in 2019 . The distribution of samples by marital status changed, showing an increase while maintaining the same structure. Married polygamous couples decreased from $39.1 \%$ in 2018 to $36.6 \%$ in 2019 , but the difference was not significant. The predominance of Ouolofs and Poulars still marked the structure by ethnic group, followed by Moors to a lesser extent. Almost all of the women surveyed were Muslim, and almost half reported that the health facility was far from their home (Table 1).

Table 1. Characteristics of the participants (women).

\begin{tabular}{|c|c|c|c|c|c|c|}
\hline & & \multicolumn{4}{|c|}{ Year } & \multirow{3}{*}{$\frac{\mathrm{X}^{2} / \mathrm{t}}{p}$} \\
\hline & & \multicolumn{2}{|c|}{2018} & \multicolumn{2}{|c|}{2019} & \\
\hline & & $n$ & $\%$ & $n$ & $\%$ & \\
\hline \multirow{5}{*}{ Age } & $<25$ years & 88 & $34.8 \%$ & 261 & $39.0 \%$ & $1.831(0.767)$ \\
\hline & 25-29 years & 62 & $24.5 \%$ & 144 & $21.5 \%$ & \\
\hline & 30-34 years & 53 & $20.9 \%$ & 141 & $21.0 \%$ & \\
\hline & 35-39 years & 33 & $13.0 \%$ & 79 & $11.8 \%$ & \\
\hline & 40-49 years & 17 & $6.7 \%$ & 45 & $6.7 \%$ & \\
\hline Age & Mean \pm SD & 22.78 & 6.80 & 27.49 & 7.01 & $0.330(0.566)$ \\
\hline \multirow{5}{*}{ Ethnic group } & Ouolof/Lebou & 141 & $55.7 \%$ & 339 & $50.6 \%$ & $7.687(0.262)$ \\
\hline & Poular & 101 & $39.9 \%$ & 314 & $46.9 \%$ & \\
\hline & Serere & 2 & $0.8 \%$ & 3 & $0.4 \%$ & \\
\hline & Moor & 7 & $2.8 \%$ & 12 & $1.8 \%$ & \\
\hline & Others & 2 & $0.8 \%$ & 1 & $0.1 \%$ & \\
\hline \multirow{5}{*}{ Education level } & Out-of-school & 165 & $65.2 \%$ & 357 & $53.3 \%$ & $13.282(0.010)$ \\
\hline & Koranic & 34 & $13.4 \%$ & 152 & $22.7 \%$ & \\
\hline & Primary & 40 & $15.8 \%$ & 113 & $16.9 \%$ & \\
\hline & Secondary & 13 & $5.1 \%$ & 45 & $6.7 \%$ & \\
\hline & University & 1 & $0.4 \%$ & 3 & $0.4 \%$ & \\
\hline
\end{tabular}


Table 1. Cont.

\begin{tabular}{|c|c|c|c|c|c|c|}
\hline & & \multicolumn{4}{|c|}{ Year } & \multirow{3}{*}{$\frac{\mathrm{X}^{2} / \mathrm{t}}{p}$} \\
\hline & & \multicolumn{2}{|c|}{2018} & \multicolumn{2}{|c|}{2019} & \\
\hline & & $n$ & $\%$ & $n$ & $\%$ & \\
\hline \multirow{3}{*}{ Marriage status } & Married (monogamous) & 149 & $58.9 \%$ & 418 & $62.4 \%$ & $1.915(0.384)$ \\
\hline & Married (polygamous) & 99 & $39.1 \%$ & 245 & $36.6 \%$ & \\
\hline & Others & 5 & $2.0 \%$ & 7 & $1.0 \%$ & \\
\hline \multirow{2}{*}{ Religion } & Muslim & 253 & $100.0 \%$ & 669 & $99.9 \%$ & $0.378(0.539)$ \\
\hline & Christian & 0 & $0.0 \%$ & 1 & $0.1 \%$ & \\
\hline $\begin{array}{l}\text { Number of } \\
\text { children }\end{array}$ & Mean \pm SD & 3.61 & 2.25 & 3.41 & 2.20 & $1.461(0.227)$ \\
\hline \multirow{4}{*}{$\begin{array}{l}\text { Level of proximity } \\
\text { of health facility }\end{array}$} & Very close & 39 & $15.4 \%$ & 69 & $10.3 \%$ & $11.921(0.008)$ \\
\hline & Close & 90 & $35.6 \%$ & 278 & $41.5 \%$ & \\
\hline & Distant & 62 & $24.5 \%$ & 203 & $30.3 \%$ & \\
\hline & Very distant & 62 & $24.5 \%$ & 120 & $17.9 \%$ & \\
\hline
\end{tabular}

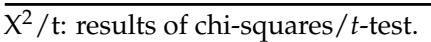

The average age (40 years) of men remained the same in both surveys as did the age group structure. The level of education was still dominated by Koranic education (58.3\% in 2019 against $71.1 \%$ in 2018). However, the numbers of those who had attended formal school was higher in 2019 , with $17.9 \%$ of the respondents compared to $10.1 \%$ in 2018. Moreover, similar to women, almost all the men interviewed during the mid-term evaluation were married and Muslim. The same applied to their ethnic group, which was, in most cases, Ouolof or Poular (Table 2). Overall, despite slight differences in the socio-demographic characteristics of respondents (male and female) in both surveys, the outcomes are comparable because a few of the chi-square tests between 2018 and 2019 were statistically significant (educational level and level of proximity of health facility among women).

Table 2. Characteristics of the participants (men).

\begin{tabular}{|c|c|c|c|c|c|c|}
\hline & & \multicolumn{4}{|c|}{ Year } & \multirow{3}{*}{$\frac{\mathrm{X}^{2} / \mathrm{t}}{p}$} \\
\hline & & \multicolumn{2}{|c|}{2018} & \multicolumn{2}{|c|}{2019} & \\
\hline & & $n$ & $\%$ & $n$ & $\%$ & \\
\hline \multirow{3}{*}{ Survey district } & Keur Momar Sarr & 60 & $26.7 \%$ & 223 & $33.2 \%$ & $3.505(0.173)$ \\
\hline & Coki & 79 & $35.1 \%$ & 222 & $33.1 \%$ & \\
\hline & Sakal & 86 & $38.2 \%$ & 226 & $33.7 \%$ & \\
\hline \multirow{6}{*}{ Age } & $<25$ years & 4 & $1.8 \%$ & 32 & $4.8 \%$ & $10.797(0.056)$ \\
\hline & 25-29 years & 22 & $9.8 \%$ & 84 & $12.5 \%$ & \\
\hline & 30-34 years & 36 & $16.0 \%$ & 114 & $17.0 \%$ & \\
\hline & 35-39 years & 49 & $21.8 \%$ & 103 & $15.4 \%$ & \\
\hline & 40-49 years & 59 & $26.2 \%$ & 199 & $29.7 \%$ & \\
\hline & 50 years or more & 55 & $24.4 \%$ & 139 & $20.7 \%$ & \\
\hline Age & Mean \pm SD & 40.76 & 9.9 & 40.05 & 10.40 & $0.906(0.365)$ \\
\hline
\end{tabular}


Table 2. Cont.

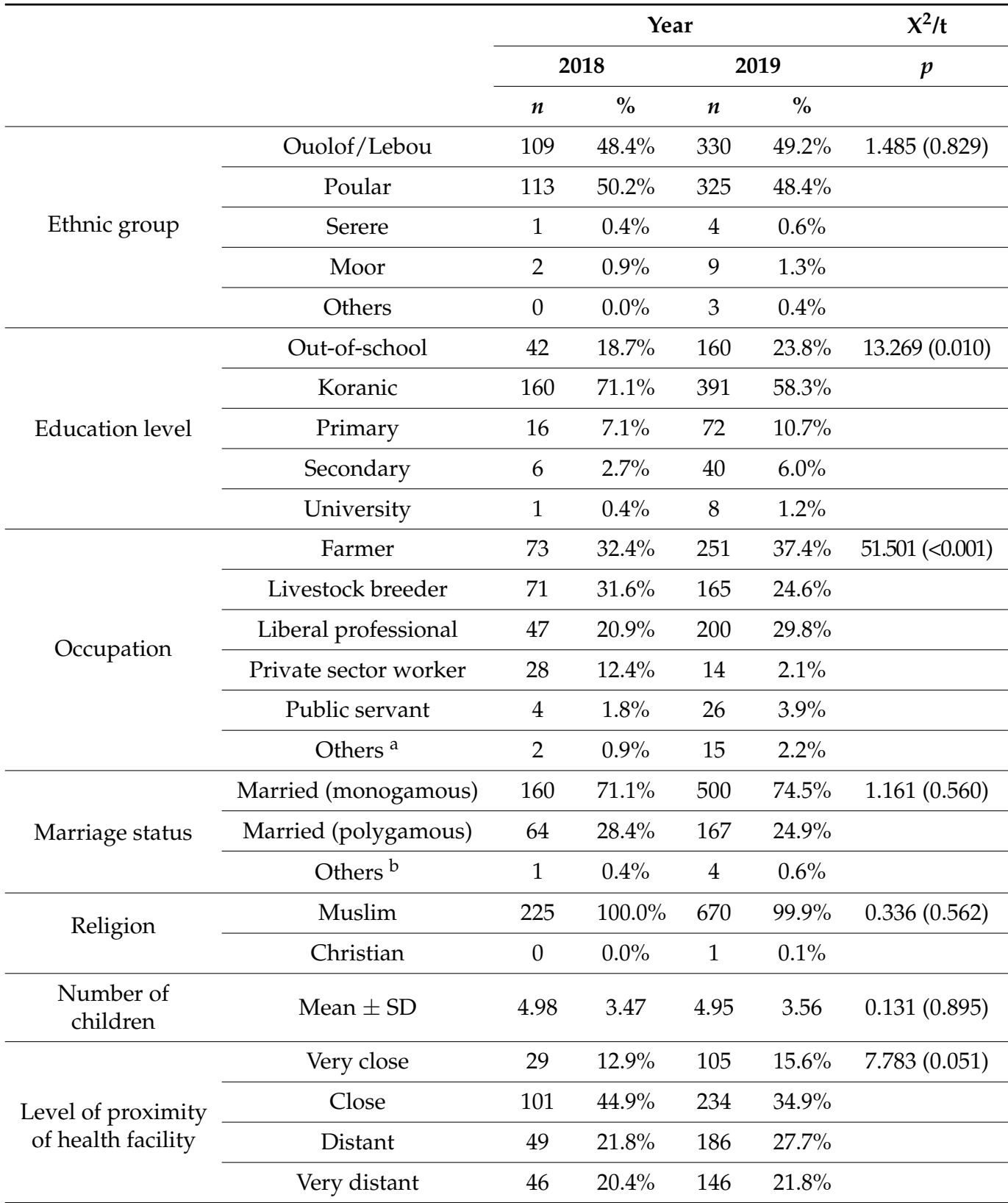

a: emigrant, ${ }^{b}$ : divorced/separated, widower/widowed; $X^{2} / t$ : results of chi-squares/t-test.

\subsection{Awareness of Danger Signs of Pregnancy}

The level of awareness of at least three danger signs of pregnancy indicated awareness of men significantly increased between 2018 and 2019: 14.2\% against 20.9\% $(p=0.029)$ (Table 3). The best-known signs for men in 2019 were severe stomach pain, followed by vaginal bleeding and intense fever, while in 2018, intense fever was mentioned first. However, awareness among women decreased slightly (45.8\% in 2018 compared to $41.5 \%$ in 2019). 
Table 3. The effects of maternal health improvement project focusing on IEC activities.

\begin{tabular}{|c|c|c|c|c|c|c|c|c|}
\hline & & & & \multicolumn{2}{|c|}{2018} & \multicolumn{2}{|c|}{2019} & \multirow{2}{*}{$X^{2}(p)$} \\
\hline & & & & $n$ & $\%$ & $n$ & $\%$ & \\
\hline \multirow{4}{*}{\multicolumn{2}{|c|}{$\begin{array}{l}\text { Awareness of danger signs of } \\
\text { pregnancy }\end{array}$}} & \multirow{2}{*}{ Males } & $<3$ signs & 193 & $85.8 \%$ & 531 & $79.1 \%$ & \multirow{2}{*}{$4.793(0.029)$} \\
\hline & & & $\geq 3$ signs & 32 & $14.2 \%$ & 140 & $20.9 \%$ & \\
\hline & & \multirow{2}{*}{ Females } & $<3$ signs & 137 & $54.2 \%$ & 392 & $58.5 \%$ & \multirow{2}{*}{$1.425(0.233)$} \\
\hline & & & $\geq 3$ signs & 116 & $45.8 \%$ & 278 & $41.5 \%$ & \\
\hline \multirow{2}{*}{\multicolumn{3}{|c|}{$\begin{array}{l}\text { Accompany their wives during ANC visits } \\
\text { (female) }\end{array}$}} & No & 215 & $85.3 \%$ & 517 & $77.7 \%$ & \multirow{2}{*}{$6.508(0.010)$} \\
\hline & & & Yes & 37 & $14.7 \%$ & 148 & $22.3 \%$ & \\
\hline \multirow{2}{*}{\multicolumn{3}{|c|}{$\begin{array}{c}\text { Acknowledged having received the support of } \\
\text { their husband/partner during their last } \\
\text { pregnancy (female) }\end{array}$}} & No & 6 & $2.4 \%$ & 6 & $0.9 \%$ & $3.118(0.077)$ \\
\hline & & & Yes & 247 & $97.6 \%$ & 664 & $99.1 \%$ & \\
\hline \multirow{2}{*}{\multicolumn{3}{|c|}{ Delivery appropriate health facilities (female) }} & No & 44 & $17.7 \%$ & 96 & $14.4 \%$ & $1.461(0.227)$ \\
\hline & & & Yes & 205 & $82.3 \%$ & 569 & $85.6 \%$ & \\
\hline \multirow{6}{*}{$\begin{array}{l}\text { Women's } \\
\text { empowerment }\end{array}$} & \multirow{2}{*}{\multicolumn{2}{|c|}{ Making own health decisions }} & $\begin{array}{l}\text { Only by } \\
\text { wife }\end{array}$ & 21 & $8.3 \%$ & 122 & $18.2 \%$ & $21.935(<0.001)$ \\
\hline & & & $\begin{array}{l}\text { Other than } \\
\text { wife }^{\text {a }}\end{array}$ & 232 & $91.7 \%$ & 548 & $81.8 \%$ & \\
\hline & \multirow{2}{*}{\multicolumn{2}{|c|}{$\begin{array}{c}\text { Joining a community } \\
\text { decision-making association } \\
\text { or group }\end{array}$}} & No & 175 & $69.2 \%$ & 309 & $46.1 \%$ & $39.125(<0.001)$ \\
\hline & & & Yes & 78 & $30.8 \%$ & 361 & $53.9 \%$ & \\
\hline & \multirow{2}{*}{\multicolumn{2}{|c|}{$\begin{array}{l}\text { Disagreement about using a } \\
\text { method of contraception }\end{array}$}} & No & 166 & $65.6 \%$ & 511 & $76.3 \%$ & $10.667(0.001)$ \\
\hline & & & Yes & 87 & $34.4 \%$ & 159 & $23.7 \%$ & \\
\hline
\end{tabular}

${ }^{a}$ : By both husband and wife, husband/partner, mother-in-law.

\subsection{Husbands Accompany Their Wives during ANC Visits}

In 2019, husbands/partners more frequently accompanied their wives during ANC visits than in 2018: $22.3 \%$ compared to $14.7 \%(p=0.010)$. The main reasons for non-support in 2019 remained the same as in 2018-absence of the husband/partner, respect of the customs, or preoccupation with work.

\subsection{Acknowledged Receiving Support of Husband/Partner during Last Pregnancy}

As in 2018, almost all the women interviewed (99.1\% in 2019 compared to $97.6 \%$ in 2018) acknowledged having received the support of their husband/partner during their last pregnancy, but there was no significant difference by year. Support for medical costs remained the primary type of support received. The main reasons for lack of support in 2018 and 2019 were the husband's absence or conflicts in the couple's relationship.

\subsection{Delivery at Appropriate Health Facilities}

Delivery, which is one of the crucial phases of maternity, was carried out mainly at appropriate health facilities with an increased percentage in 2019-85.6\% compared to $82.3 \%$ in 2018-but the increase was not significant. The clinics, health centres, health huts, health posts, and hospitals were regarded as appropriate health facilities. The main reasons for home delivery in 2018 and 2019 were insufficient time to join a health facility, the lack of transportation means, and the facilities' remoteness.

\subsection{Women's Empowerment}

Women's empowerment improved significantly. In 2018, only 8.3\% of women declared that they made their own health decisions compared to $18.2 \%$ in $2019(p<0.001)$. More women joined community decision-making associations or groups ( $30.8 \%$ in 2018 versus 
$53.9 \%$ in 2019, $p<0.001)$. Men's opposition to their wives/partners using contraception (34.4\% in 2018 versus $23.7 \%$ in 2019$)$ significantly decreased ( $p=0.001)$.

\section{Discussion}

This study aimed to confirm the effectiveness of the IEC activities as part of the Plan International Senegal project implemented to reduce maternal and child mortality in the Louga region of Senegal, and to identify related factors that can improve maternal and child health.

Most developing countries in Africa, including Senegal, have strong patriarchal tendencies, thus men exercise absolute control over women and control women's fundamental health decisions and lifestyles. Therefore, measures to enhance women's autonomy are actively sought [11-13]. For example, under Agenda 2063, which is being promoted by the African Union in relation to the SDGs to further the universal principles of women's human rights and aim to achieve complete gender equality in all areas of life, efforts have been made to ensure quality education is provided to women [14]. However, despite such efforts, the illiteracy rate of women in Africa remains high at 43.47-86.2\% [15-17].

In this study, we found most of the men and women interviewed were young and illiterate. Regarding the reduction of maternal mortality, this situation may be cause for concern given the critical role that education can play in raising women's awareness about the importance of their involvement in decision-making associated with their or their children's health. The illiteracy rate of women participating in this study was high at $65.2 \%$ in 2018 and $53.3 \%$ in 2019. According to previous studies, the mother's education level is an important factor that has a significant influence on the medical service utilisation rate; the higher the education level, the higher the rate of prenatal examination and delivery at facilities [11-13,15,17,18]. Mothers with low educational attainment do not receive antenatal examinations, which prevent the early detection of complications that may occur during pregnancy and the opportunity for timely appropriate treatment is missed, resulting in increased disease morbidity $[13,19]$. A high rate of delivery at home increases the risk of complications due to the inability to cope with unexpected situations such as maternal bleeding and risk of suffocation of the newborn infant during childbirth $[19,20]$. Therefore, to effectively reduce the maternal mortality rate, efforts need to be made to improve educational opportunities that directly influence women's use of medical services. However, the customs of child marriage and economic poverty in Africa are reported to be the most significant obstacles limiting women's educational opportunities [21,22]. Efforts are needed to implement short- and long-term policies to improve them.

An institutional framework for continuous economic growth of the international community in developing countries, abolition of women's early marriage customs, and a legal framework that makes education above the minimum education level compulsory should be considered under long-term policies. Health education for disadvantaged and poor residents in developing countries will be an effective alternative in the short-term.

The effectiveness of health education that provided information such as reproductive health as well as prenatal and postpartum precautions was studied through the IEC campaign (e.g., conversations, radio shows, home visits, and social mobilisations), and the effectiveness was confirmed by comparing the results before and after the activities. The proportion of men who agreed to the contraceptive method suggested by the wife and to the wife's autonomy to participate in community associations or groups increased statistically significantly after the IEC campaign.

An effective method to reduce maternal mortality is to increase knowledge of pregnancy danger signs. Knowledge of pregnancy-related danger signs enables the adoption of appropriate preventive and curative behaviours. In this study, after the IEC campaign, men's knowledge of the signs of danger related to pregnancy and the husband's companionship during prenatal examinations increased statistically significantly compared to before the campaign. The percentage of respondents who answered that they received support from their husbands during pregnancy did not show any statistical significance 
but did show an increase compared to before the implementation of IEC activities. In developing countries, the male plays the role of the decision-maker in the household, thus being aware of when to actively support women during pregnancy or reacting sensitively to the women's abnormal signal is important to the improvement of women's health by increasing the use of prenatal medical services [23-26]. Therefore, previous studies are continuing research on methods to increase the participation of spouses and are actively trying to resolve negative factors. In a previous study [23] conducted in Rwanda, when the husband's participation in pregnancy and childbirth was high, the husband helped with housework or provided medical expenses on the treatment date. However, in cases where the husband's participation was low, they did not recognise the importance of the antenatal check-up performed before childbirth and did not allow treatment of the spouse.

In a previous study conducted in India [24] to promote male participation in supporting maternal health, the aspects of personal, community, and healthcare were analysed to determine if they acted as facilitating factors or obstacles, and a way to overcome the obstacles was sought. Concerning the personal aspect, the higher the level of education and income, the greater the degree to which the knowledge and awareness of medical services were facilitating factors. It was reported that an obstacle to the participation of men is their system of values, as they value norms and beliefs, attitudes toward gender inequality, and lower participation of women. In the local community, social norms and expectations, and the level of practice of maternal healthcare were found to be factors influencing male participation in women's maternal health care. The access time, distance, and location of medical facilities, government plans, and programs were healthcare factors that influenced male participation. Daniele [25] found that the level of male participation was determined by various factors. The health care system and its attitude, knowledge, and skills of health care workers regarding prenatal examination and childbirth act as supply factors, and regional attitudes, norms, and male and female preferences change their interaction as demand factors based on the theory of change. That is, if there are no restrictions placed on men in medical facilities, the medical staff view men's participation positively, and the accompaniment of the spouse for prenatal examinations and childbirth does not go against traditional norms, the level of men's participation increases. In addition, some women are ashamed of the process of prenatal examination and childbirth being carried out by male medical staff, and it was found that they prefer female companions because they do not want to show their spouses the exam process, are shy, and believe they should endure the whole process of pregnancy alone. Such narrow thinking about women's gender roles can act as a powerful factor inhibiting men's participation. It is necessary to educate women so they understand that pregnancy and childbirth are not an experience to be ashamed of, but are extremely important affairs to all families, to society, and to the country.

Many factors that inhibit male prenatal participation may be acting in Senegal; thus, multiple approaches are needed to improve this. The low educational level of men has been reported to be associated with greater adherence to cultural traditions and beliefs [9]. Improving this situation requires the provision of compulsory formal education in addition to the provision of health education through media, which has proven to be effective in improving knowledge of prenatal care [27]. From a community point of view, one method to increase male participation in ANC is to have the village's authoritative leader recommend that women villagers attend ANC visits with a male spouse as a formal community rule. In areas where ambulances do not have access due to a lack of roads, providing villagers with practical means of transportation such as bicycles or donkey carts, according to the characteristics of the terrain, would enable villagers not only to cope with maternal emergency situations but also to receive appropriate ANC [8]. Lastly, in the case of men accompanying their wives to a medical facility, in many cases they are required to remain in the waiting area and choose an isolated place outside the medical facility until the treatment is completed [28]. In addition, the attitude of medical staff who fail to encourage male participation in the ANC process is perceived as a negative experience, which reduces active participation among men $[24,25]$. Therefore, facilities should encourage and educate 
men to get involved in the entire process of prenatal care and childbirth. In addition, for women with limited social relationships, the space for receiving prenatal care needs to be not just a physical place but a space in which they can form social relationships with other pregnant women and share reproductive health information. Therefore, changes in social norms are necessary to enhance women's autonomy and to recognise that the medical waiting space is a space that includes men, not just women [28].

Although it did not show a statistically significant value, the response rate for childbirth at appropriate facilities did show an increase. According to previous studies, education promotes self-esteem and self-awareness that enable autonomous decision-making [15,29,30]. Women's autonomy is the ability to make personal decisions regardless of their spouse's preferences in the home [31], which means improved access to potentially life-saving services for themselves and their children [15], leading to increased use of medical services [13,15,29-31]. In addition, women with higher levels of autonomy do not think their rights belong to their spouses but instead believe in a relationship of equality; thus, these women are reported to have implemented family planning using contraceptive methods through effective communication [18,32]. The team of advocates trained by the Korea International Cooperation Agency (KOICA) project promotes awareness through various avenues (conversations, radio shows, home visits, and social mobilisations), urging the population to undergo delivery procedures at appropriate health facilities, for which targets have been achieved or exceeded. However, efforts still need to be made to avoid home deliveries and further improve the condition of facilities to ensure they are welcoming and efficiently care for patients. Most medical facilities in developing countries are not fully functional in terms of infrastructure and resources. In the case of rural areas, there is a lack of transportation and reaching a facility to receive medical services requires extensive travel. In addition, medicines and materials at medical institutions may be insufficient, and in some cases, medical staff are not villagers and may be unprofessional and unfriendly to caregivers and patients $[25,26]$. Regardless, regular ANC visits and safe delivery, which are basic rights to ensure the mother's health during pregnancy, should be guaranteed. Therefore, educating women about their rights and national efforts to build systematic medical facilities should be planned and implemented. Improvement of road infrastructure and availability of emergency transport in communes to facilitate the evacuation of women to health facilities are also needed.

In this study, women's empowerment encouraged them to make decisions about health care, join community activities, and use contraception. In 1994, the International Conference on Population and Development (ICPD) acknowledged that 'the goal of the empowerment and autonomy of women and the improvement of their political, social, economic and health status is a highly important end in itself and is essential for the achievement of sustainable development' [33]. Bodily autonomy includes the power to make decisions on health care and contraception, and to decline sexual advances. In Western Africa, where Senegal is located, the levels of power to decide on contraception and health care are $88 \%$ and $59 \%$, respectively, which are relatively low compared to the world averages of $91 \%$ and $75 \%$, respectively. Additionally, Senegal shows lower percentages compared to the average of Western African countries, 85\% and 31\%, respectively; moreover, the district in this study, in the lower Senegal regions, show even lowers percentages of $76.3 \%$ and $18.2 \%$, even after accounting for the better statistics of 2019. According to the ecological model of bodily autonomy, determinants of women's decision-making power include gender norms, stigma, and beliefs (community); proximity, cost, quality of care, and provider bias (health systems); the position of partners, communication, and extended family (interpersonal); and education, wealth, media access, and rural/urban area (socioeconomic) [34]. To improve women's bodily autonomy and achieve empowerment in Senegal, individuals, families, communities, and the state should operate various policies and programs taking these factors into account.

This project-based evaluation study did not design a control group and used a repeated cross-sectional design. This was a limitation of the study. Another limitation was the 
inability to evaluate effectiveness based on the intervention dosage. Considering these limitations for further studies, it is recommended that evidence is provided by designing a control group and monitoring intervention dosage in a more systematic and scientifically rigorous way.

\section{Conclusions}

In conclusion, short-term education through the IEC campaign in Louga, resulted in improved knowledge of pregnancy among men, more accompaniment of women by husbands/partners, and improvement of women's empowerment. The IEC activities provide an opportunity to handle the obstacles that occur during prenatal care. The results of this study are applicable to other regions of Senegal and West Africa, but caution is required in East Africa, where religion, climate, society, culture, and healthcare delivery systems are different among the countries of Sub-Saharan Africa. In future, a communitybased integrated project to improve women's health and reduce maternal mortality in Senegal is recommended.

Author Contributions: Y.Y.: methodology and conceptualisation; Y.Y.: software; Y.Y. and K.K.: validation, Y.Y. and K.K.: formal analysis; Y.Y. and L.T.: investigation; B.N.: resources; B.N., G.H. and Y.C.: data curation; B.N., G.H. and Y.C.: writing-original draft preparation; Y.Y. and E.L.: writing-review and editing; Y.Y., E.L. and G.H.: visualization; B.N.: supervision; Y.C.: project administration; B.N.: funding acquisition; G.H. and Y.C. All authors have read and agreed to the published version of the manuscript.

Funding: This research was funded by the Korea International Cooperation Agency (KOICA) as a project of the "Maternal Health Improvement Project in the Louga Region of Senegal" (grant number: 2018-036-01) and the KOICA as a project of performance management for public-private cooperation programs at health and other sectors (grant number: P2018-00067-1).

Institutional Review Board Statement: This study was approved by the National Health Research Ethics Committee (CNERS) (approval number for the baseline survey: Ethical and scientific notice $\mathrm{N}^{\circ}$ 000084/MSAS/DPRS/CNERS dated 31 August 2018 for midterm survey: $\mathrm{N}^{\circ}$ 000165/MSAS/DPRS/CNERS dated 6 September 2019).

Informed Consent Statement: All the participants provided their informed written consent.

Data Availability Statement: All databases are available from the corresponding author upon request.

Acknowledgments: The authors would like to acknowledge all communities and partners for their support and sharing their opinions.

Conflicts of Interest: The authors have no conflict of interest to declare.

\section{References}

1. WHO. 2021. Available online: https:/ / www.who.int/health-topics/maternal-health\#tab=tab_1 (accessed on 10 October 2021).

2. WHO. 2021. Available online: https://www.who.int/news-room/fact-sheets/detail/millennium-development-goals-(mdgs) (accessed on 10 October 2021).

3. WHO. 2021. Available online: https://www.who.int/news-room/fact-sheets/detail/maternal-mortality (accessed on 10 October 2021).

4. Ministry of Health and Social Welfare. National Family Planning Action Plan 2012-2015 (Strategic Plan for Reproductive Health). 2015. Available online: http://ec2-54-210-230-186.compute-1.amazonaws.com/wp-content/uploads/2014/10/Senegal_ National_FP_Action_Plan_English.pdf (accessed on 10 October 2021).

5. African Child Policy Forum. 2007. Available online: https://africanchildforum.org/index.php/en/ (accessed on 10 October 2021).

6. Tokhi, M.; Comrie-Thomson, L.; Davis, J.; Portela, A.; Chersich, M.; Luchters, S. Involving men to improve maternal and newborn health: A systematic review of the effectiveness of interventions. PLoS ONE 2018, 13, e0191620. [CrossRef]

7. Lee, H.; Park, S.J.; Ndombi, G.O.; Nam, E.W. Community-based maternal and child health project on 4+ antenatal care in the Democratic Republic of Congo: A difference-in-differences analysis. Reprod. Health 2019, 16, 157. [CrossRef] [PubMed]

8. Ensor, T.; Green, C.; Quigley, P.; Badru, A.R.; Kaluba, D.; Kureya, T. Mobilizing communities to improve maternal health: Results of an intervention in rural Zambia. Bull. World Health Organ. 2013, 92, 51-59. [CrossRef] [PubMed] 
9. Bang, K.-S.; Chae, S.-M.; Lee, I.; Yu, J.; Kim, J. Effects of a Community Outreach Program for Maternal Health and Family Planning in Tigray, Ethiopia. Asian Nurs. Res. 2018, 12, 223-230. [CrossRef] [PubMed]

10. WHO. Senegal Country Cooperation Strategy at a Glance, Continuous EDS 2015. 2015. Available online: https://www.who.int/ countries/sen/ (accessed on 10 October 2021).

11. Ahuru, R.R. The influence of women empowerment on maternal and childcare use in Nigeria. Int. J. Health Manag. 2021, 14, 690-699. [CrossRef]

12. Yakubu, Y.; Nor, N.M.; Abidin, E.Z. A systematic review of micro correlates of maternal mortality. Rev. Environ. Health 2018, 33, 147-161. [CrossRef] [PubMed]

13. Hassan, H.K.; Basirka, I.A. Healthcare seeking behavior and utilization of maternal healthcare services among women of reproductive age in Northwest, Nigeria. Gusau Int. J. Manag. Soc. Sci. 2021, 4, 17.

14. African Union. 2021. Available online: https://au.int/agenda2063/sdgs (accessed on 10 October 2021).

15. Singh, K.; Bloom, S.; Brodish, P. Gender Equality as a Means to Improve Maternal and Child Health in Africa. Health Care Women Int 2013, 36, 57-69. [CrossRef] [PubMed]

16. Fenta, S.M.; Ayenew, G.M.; Getahun, B.E. Magnitude of antenatal care service uptake and associated factors among pregnant women: Analysis of the 2016 Ethiopia Demographic and Health Survey. BMJ Open 2021, 11, e043904. [CrossRef]

17. Gora, G.; Umer, M.; Ojulu, P.; Betaw, S.; Cham, A.; Gora, O.; Qi, X. Non-Institutional Childbirths and the Associated SocioDemographic Factors in Gambella Regional State, Ethiopia. Int. J. Environ. Res. Public Health 2021, 18, 2859. [CrossRef] [PubMed]

18. Zegeye, B.; Ahinkorah, B.O.; Idriss-Wheeler, D.; Olorunsaiye, C.Z.; Adjei, N.K.; Yaya, S. Modern contraceptive utilization and its associated factors among married women in Senegal: A multilevel analysis. BMC Public Health 2021, 21, 231. [CrossRef]

19. Kumar, A.M.; Aravindan, J.; Indira, N.; Choudhary, A.K. A community-based study on obstetric danger signs among pregnant women of Sivagangai district. Age 2020, 20, 12.9.

20. Ibrahima, A.B. Exploring Maternal Health in Ethiopia Using Indigenous Approaches: Policy and Practice Implications Res. Soc. Work. Pr. 2021, 31, 343-350. [CrossRef]

21. Sagalova, V.; Nanama, S.; Zagre, N.M.; Vollmer, S. Long-term consequences of early marriage and maternity in West and Central Africa: Wealth, education, and fertility. J. Glob. Health 2021, 11, 11. [CrossRef] [PubMed]

22. Atake, E. Socio-economic inequality in maternal health care utilization in Sub-Saharan Africa: Evidence from Togo. Int. J. Health Health Plan. Manag. 2021, 36, 288-301. [CrossRef]

23. Tuyisenge, G.; Crooks, V.A.; Berry, N.S. "He lets me go although he does not go with me.": Rwandan women's perceptions of men's roles in maternal health. Glob. Health Health Res. Policy 2021, 6, 2. [CrossRef]

24. Nair, S.; Adhikari, T.; Juneja, A.; Gulati, K.B.; Kaur, A.; Rao, M.V.V. Community Perspectives on Men's Role in the Utilisation of Maternal Health Services Among Saharia Tribes in Gwalior, Madhya Pradesh, India: Insights from a Qualitative Study. Matern. Child Health Health J. 2021, 25, 769-776. [CrossRef]

25. Daniele, M.A.S. Male partner participation in maternity care and social support for childbearing women: A discussion paper. Philos. Trans. R. Soc. B Biol. Sci. 2021, 376, 20200021. [CrossRef] [PubMed]

26. Boniphace, M.; Matovelo, D.; Laisser, R.; Swai, H.; Yohani, V.; Tinka, S.; Mwaikasu, L.; Mercader, H.; Brenner, J.L.; Mitchell, J. Men perspectives on attending antenatal care visits with their pregnant partners in Misungwi district, rural Tanzania: A qualitative study. BMC Pregnancy Childbirth 2021, 21, 93. [CrossRef]

27. Sapkota, V.P.; Bhusal, U.P.; Acharya, K. Trends in national and subnational wealth related inequalities in use of maternal health care services in Nepal: An analysis using demographic and health surveys (2001-2016). BMC Public Health 2021, 21, 8. [CrossRef] [PubMed]

28. Ampim, G.A.; Blystad, A.; Kpoor, A.; Haukanes, H. “I came to escort someone”: Men's experiences of antenatal care services in urban Ghana-A qualitative study. Reprod. Health 2021, 18, 106. [CrossRef] [PubMed]

29. Tesema, G.A.; Yeshaw, Y.; Kasie, A.; Liyew, A.M.; Teshale, A.B.; Alem, A.Z. Spatial clusters distribution and modelling of health care autonomy among reproductive-age women in Ethiopia: Spatial and mixed-effect logistic regression analysis. BMC Health Health Serv. Res. 2021, 21, 74. [CrossRef] [PubMed]

30. Gelaw, B.; Lankrew, T.; Assefa, A.; Demeke, T. Women's Decision-Making Autonomy in Maternal Health Service Utilization and Associated Factors among Reproductive Age Women in Southern, Ethiopia. 2021. Research Square. Available online: https: / / assets.researchsquare.com/files/rs-521248/v1/cb724642-ae65-44c6-9923-38d17f5e0828.pdf?c=1631883034 (accessed on 10 October 2021). [CrossRef]

31. Sano, Y.; Antabe, R.; Atuoye, K.N.; Braimah, J.A.; Galaa, S.Z.; Luginaah, I. Married women's autonomy and post-delivery modern contraceptive use in the Democratic Republic of Congo. BMC Women's Health 2018, 18, 49. [CrossRef] [PubMed]

32. Kabagenyi, A.; Wasswa, R.; Henry, N.; Paulino, A.; Sseninde, J.; Rusatira, J.C. Multilevel Mixed Effects Analysis of Individual and Community Factors Associated with Unmet Need for Contraception Among Married Women in Four East African Countries. 2021. Research Square. Available online: https://assets.researchsquare.com/files/rs-470884/v1_covered.pdf?c=1631865844 (accessed on 10 October 2021). [CrossRef] 
33. UNFPA. Report of the International Conference on Population and Development, Cairo, 5-13 September 1994. Available online: https://www.un.org/development/desa/pd/sites/www.un.org.development.desa.pd/files/icpd_en.pdf (accessed on 10 October 2021).

34. Erken, A.; Baker, D.; Behrendt, A.; Baric, B.; Deville, M.; Ferguson, L.; Luchsinger, G.; Roseman, M. State of World Population 2021. My Body Is My Own. Claiming the Right to Autonomy and Self-Determination. 2021. Available online: https://www. unfpa.org/sites/default/files/pub-pdf/SoWP2021_Report_-_EN_web.3.21_0.pdf (accessed on 10 October 2021). 